\title{
Curriculum system for experimental teaching in optoelectronic information
}

Hongwei Di, Zhenqiang Chen, Jun Zhang, Yunhan Luo

Hongwei Di, Zhenqiang Chen, Jun Zhang, Yunhan Luo, "Curriculum system for experimental teaching in optoelectronic information," Proc. SPIE 10452, 14th Conference on Education and Training in Optics and Photonics: ETOP 2017, 104524R (16 August 2017); doi: 10.1117/12.2269160

SDIE Event: 14th Conference on Education and Training in Optics and Photonics, ETOP 2017, 2017, Hangzhou, China 


\title{
Curriculum system for experimental teaching in optoelectronic information
}

\author{
Hongwei Di*a ${ }^{*}$, Zhenqiang Chen ${ }^{\mathrm{a}}$, Jun Zhang ${ }^{\mathrm{a}}$,Yunhan Luo ${ }^{\mathrm{a}}$ \\ ${ }^{a}$ Department of OptoElectronic Engineering, Jinan University, Guangzhou,Guangdong 510632 , \\ China
}

\begin{abstract}
The experimental curriculum system is directly related to talent training quality. Based on the careful investigation of the developing request of the optoelectronic information talents in the new century, the experimental teaching goal and the content, the teaching goal was set to cultivate students' innovative consciousness, innovative thinking, creativity and problem solving ability. Through straightening out the correlation among the experimental teaching in the main courses, the whole structure design was phased out, as well as the hierarchical curriculum connotation. According to the ideas of "basic, comprehensive, applied and innovative", the construction of experimental teaching system called "triple-three" was put forward for the optoelectronic information experimental teaching practice.
\end{abstract}

Keywords: "Triple-three" curriculum system, experimental teaching, optoelectronic information

\section{INTRODUCTION}

Experimental teaching is an important part of teaching work in institutions of higher learning. It is the main route to cultivate the ability of analyzing and solving problem, the spirit of innovation, the quality of comprehensiveness for students. Today, the importance of experimental teaching in talent training is getting more and more obvious, so universities consider it as a significant aspect of enhancing talents' quality and deepening the educational reform ${ }^{[1][2]}$. Based on the careful investigation of the developing request of the optoelectronic information talents, the experimental teaching goal and the content in the new century, the teaching goal is set to fully implement quality education, cultivate students' innovative consciousness, innovative thinking, creativity and the ability of solving problem in Jinan University. Through accurately grasping teaching objective, straightening out the correlation among the experimental courses, drawing up the experimental syllabus, laying down cultivation target of experimental learning in different stage, we design the whole structure by stage and the curriculum content by layer. According to the trend of scientific development, the demand of creative talents' development, the ideas of "basic, comprehensive, applied and innovative" and the differences of students' learning purpose, learning degree, learning content, we implemented different experimental teachings by different links, different degrees and different modules to suit the developing request of creative talents. In the optoelectronic information experimental teaching practice, the construction of experimental teaching system called "triple-three" was put forward.

14th Conference on Education and Training in Optics and Photonics: ETOP 2017, edited by Xu Liu,

Xi-Cheng Zhang, Proc. of SPIE Vol. 10452, 104524R - (c) 2017 ICO, IEEE, OSA, SPIE

CCC code: $0277-786 X / 17 / \$ 18 \cdot$ doi: $10.1117 / 12.2269160$ 


\section{POSITION OF EXPERIMENTAL TEACHING}

Jinan University is an integrated, international university, which has a long history and great reputation overseas. In recent years, the university has been exploring and building the experimental teaching system which not only suits mainland students, overseas Chinese, Hong Kong, Macau, and Taiwan students, but also has the characteristic called "Overseas Chinese School \& Prestigious School". Besides, we also try very hard to make the core contents of experimental teaching, such as experimental teaching model, educational system, educational content and educational technology, suit the new demand to students' knowledge, ability and quality which brought by social progress and subject development.

With its further development, the information technology is developing towards optoelectronic technology, while the information optoelectronic industry has become one of the pillars in information industry. Experimental teaching is not only the crucial link of cultivating practical talents, implementing quality education, and cultivating high-quality talents who have the project practical ability and creativity, but also the important link which is the most creative and challenging in current optoelectronic information subject construction and educational reform ${ }^{[3]}$.

For the major of optoelectronic information, the experimental teaching should achieve the following targets.

(1) Through experimental teaching, students can obtain the opportunities to observe the scientific regular patterns and phenomena in the field of optoelectronic information. so students can further master the basic principles and notions that they learned in class.

(2) Make students know and master the basic methods of scientific research, technology and product development in the field of optoelectronic information, and be familiar with, then master the principles and using methods of all kinds of basic instruments of optoelectronic information.

(3) Make students know and master the working principle, manufacturing process, parameters, test methods and basic skills of common components in the field of optoelectronic information. On this condition, basically know and preliminary master the design and test methods of optoelectronic information systems.

(4) Cultivate students' problem solving ability, the ability of automatically raising questions, innovation consciousness, the spirit of exploration, and the general ability of problem solving.

\section{3. “TRIPLE-THREE” EXPERIMENTAL TEACHING SYSTEM}

Through years of exploration, combined with reality of Jinan University, under the practice of undergraduate experimental teaching in optoelectronic information, we proposed to construct the experimental teaching system called "triple-three" .

(1) According to the learning purposes, it divides into three experimental links: laboratory teaching, professional internship, and scientific research training.

- Through classroom experimental teaching, cultivate students' basic and comprehensive experimental skills.

- The main purpose of the professional internship is to increase the students' opportunities to contact society ${ }^{[4]}$. According to the actual demands of manufacturing, research and development, using the outside practice bases, students can get better in all links, like process flow, manufacturing technology and management. This link systematically combines the theoretical knowledge with the actual production, which plays an irreplaceable role in classroom teaching.

- Scientific research training is an important method to cultivate students' scientific research ability and innovation 
consciousness. Including : attending teachers' scientific research, the laboratory construction, all kinds of contests, extra-curricular scientific activities, etc.

(2) According to learning content, establish three experimental platforms: foundation and skills experiment platform, synthesis and design experiment platform, creativity and scientific research experiment platform.

- Foundation and skills experiment platform

The purpose is to deeply learn the basic notions of optoelectronic information engineering and enhance the direct understanding of basic optoelectronic phenomena and regular patterns for students. Besides emphasizing the organic connections between experimental content and theoretical curriculum, we also pay much attention to the rigor, inspiration, interest of experiments, and the building of students' basic practical ability.

- Synthesis and design experiment platform

The main purpose is to enhance students' understanding of professional knowledge, the synthetic training of professional skills and practical ability. According to the nature of problems, students synthetically use their knowledge, independently design the experimental plans and complete experiments. Besides emphasizing the autonomy of students while experimenting, and the inspiration and comprehensiveness of experiments, we also pay much attention to students' ability and attainment in using optoelectronic information knowledge to solve actual problems.

- Creativity and scientific research experiment platform

Based on the idea that scientific research leads the experimental teaching, we want to achieve personalized training, let students attend the whole process of research and development, and genuinely improve their researching and developing ability. Besides students' ability of raising and solving problems, this category of experiments also pay much attention to the exploration of experiment, students' creativity and the ability of working independently. On the other hand, we want more students can be benefited from attending high-level practical activities by organizing them to join the laboratory construction, developing the training class of studying the newest scientific production technology, joining the scientific research activities and enterprise-related research work, etc. The school will provide the places, devices, materials and outstanding tutors to support students attend all levels and categories of undergraduate scientific contests, such as "the Challenge Cup", the Optoelectronic Design Contest, the Innovation Project and so on, which create opportunities for good students to stand head.

(3) According to learning levels, divide into three degrees : the compulsory, the optional, and the free.

The compulsory experiment emphasizes on students' mastering of basic knowledge and cultivating of basic practical ability.

The optional experiment teaches students in accordance with their aptitude, which fully reflects the running policy of Jinan University, "Cater to foreign countries, cater to Hong Kong, Macau, and Taiwan". Different degrees of experiments are designed to different degrees of students. Among several designated experiments, based on students' degree, they can choose the one which they are interested.

The free experiment provides students with a free and comfortable experimental environment, which lets students have more time and energy to do the experiments which they are interested .Besides that, it not only can motivate students' initiative and enthusiasm in study, but also be helpful for their personality development, and the cultivating of their independent problem solving ability and creativity consciousness. Through open sharing mode, we can accomplish the modular integrated teaching of above three platforms. 


\section{SUMMARY}

Based on students' learning demand and learning ability in different levels, the experimental teaching system called "Triple-three" curriculum system, is constructed. This coherent teaching system advances in regular order, run through the whole process of undergraduate teaching, and achieves the change from the signal one, to synthesis, to independent design ,to eventual research and developing.

\section{ACKNOWLEDGMENT}

This work is sponsored by Teaching Project of Undergraduate University in Ministry of Education of the People's Republic of China, and Teaching Quality and Teaching Reform Project of Undergraduate University in Guangdong Province.

\section{REFERENCES}

[1] Xue Qiaoqiao, Wu Yuanming. Research and practice of training mode for optical engineering talent, Higher Education Forum,(7),40-43(2011).

[2] Wang Xuchu, Luo Jun. Exploration and reformation on practical teaching of optoelectronic information engineering speciality,Computer Knowledge and Technology,7(7),1710-1712(2011).

[3] Zhang Yonglin, Di Hongwei. Optoelectronic technology, Higher Education Press, Beijing, (2012).

[4] Li Dongsheng, Li Wenjun, Mao Chen. On the in-depth cooperation model in engineering education between universities and enterprise, Higher Engineering Education Research,(3),88-92(2011). 